\title{
High resolution VHF radar measurements of tropopause structure and variability at Davis, Antarctica $\left(69^{\circ} \mathrm{S}, 78^{\circ} \mathrm{E}\right)$
}

\author{
S. P. Alexander, D. J. Murphy, and A. R. Klekociuk \\ Australian Antarctic Division, Kingston, Tasmania, Australia \\ Correspondence to: S. P. Alexander (simon.alexander@aad.gov.au) \\ Received: 4 September 2012 - Published in Atmos. Chem. Phys. Discuss.: 5 October 2012 \\ Revised: 7 February 2013 - Accepted: 22 February 2013 - Published: 15 March 2013
}

\begin{abstract}
Two years of Very High Frequency (VHF) radar echo power observations are used to examine the structure and variability of the tropopause at Davis, Antarctica. Co-located radiosonde and ozonesonde launches provide data with which to calculate the lapse-rate and chemical tropopauses. The radar tropopause, defined as the maximum vertical gradient of echo return power, can be used as a definition of the Antarctic tropopause throughout the year under all meteorological conditions. During the extended summer period of December-April (DJFMA) inclusive, radar tropopauses are $(0.2 \pm 0.4) \mathrm{km}$ lower than radiosonde lapse-rate (i.e. the World Meteorological Organisation - WMO) tropopauses and during the extended winter period of June-October (JJASO) inclusive, the radar tropopauses are $(0.8 \pm 1.0) \mathrm{km}$ lower. A potential vorticity tropopause is defined as the altitude of the $-2 \mathrm{PVU}$ surface (where $1 \mathrm{PVU}=10^{6} \mathrm{~m}^{2} \mathrm{~s}^{-1} \mathrm{~K} \mathrm{~kg}^{-1}$ ). This is $(0.3 \pm 0.5) \mathrm{km}$ lower than the radar tropopause during DJFMA and $(0.5 \pm$ 1.0) $\mathrm{km}$ lower during JJASO. The radar, potential vorticity and ozone tropopauses decrease in altitude during increasingly strong cyclonic conditions, in contrast to the radiosonde WMO tropopause which remains nearly constant. During strong JJASO cyclonic conditions, there are large (several $\mathrm{km}$ ) differences between WMO tropopause altitudes and radar tropopause altitudes. A seasonal cycle in tropopause fold occurrence is observed, with approximately a three-fold increase during JJASO.
\end{abstract}

\section{Introduction}

The upper troposphere and lower stratosphere (UTLS) is the atmospheric region within a few kilometers of the tropopause. It is a highly coupled region, where radiation, dynamics, clouds and chemical processes interact on a wide variety of spatial and temporal scales (Gettelman et al., 2011). In the extratropics, baroclinic waves and atmospheric fronts enable stratosphere - troposphere exchange (STE), whereby air masses irreversibly move across the tropopause. These air masses may be followed using dynamical or chemical tracers (Hocking et al., 2007; Sprenger et al., 2003; Pan et al., 2009). The extra-tropical transition layer is the region of atmosphere where the air shows a mix of stratospheric and tropospheric properties, and is often studied using vertically-resolved trace gas profiles such as ozone and water vapour (e.g. Hegglin et al., 2009). Synoptic-scale and mesoscale processes are important for extra-tropical STE (Stohl et al., 2003), which occurs during tropopause folding (Sprenger et al., 2003; Reid and Vaughan, 2004), cut-off lows (Sprenger et al., 2007; Wernli and Sprenger, 2007) and streamers (Vaughan and Timmis, 1998). Individual tropopause folds and cut-off lows can occur over wide latitudinal extent (Sprenger et al., 2003) allowing the transfer of large amounts of air between the stratosphere and troposphere. Tropopause folds are of interest because of their role in frontogenesis, initiation of severe weather and for the STE which occurs (Sprenger et al. (2003) and references therein).

The tropopause can be defined in a variety of ways. Radiosonde data provide the parameters required to calculate the lapse rate tropopause. This is often referred to as the World Meteorological Organisation (WMO) definition of the tropopause. The WMO tropopause is the lowest altitude (above $500 \mathrm{hPa}$ ) at which the temperature lapse rate falls below $2 \mathrm{~K} \mathrm{~km}^{-1}$ and the average lapse rate within $2 \mathrm{~km}$ above this altitude does not exceed $2 \mathrm{~K} \mathrm{~km}^{-1}$ (World Meteorological Organization, 1957). 
The troposphere and stratosphere are chemically distinct regions of the atmosphere, allowing for the definition of a chemical tropopause. This tropopause is based on a threshold concentration of a trace species in a vertical profile, such as ozone (Bethan et al., 1996; Pan et al., 2004).

A tropopause based on a specified potential vorticity (PV) surface calculated from reanalysis fields may be used (Holton et al., 1995). Using the hydrostatic approximation, potential vorticity is given by:

$\mathrm{PV}=\left(\zeta_{\theta}+f\right)\left(-g \frac{\partial \theta}{\partial p}\right)$

where $\theta$ is the potential temperature, $p$ is the pressure, $g$ is the gravitational constant, $f$ is the Coriolis parameter and $\zeta_{\theta}$ is the relative vorticity on isentropic surfaces. An absolute value of $2 \mathrm{PVU}$ (where $1 \mathrm{PVU}=10^{6} \mathrm{~m}^{2} \mathrm{~s}^{-1} \mathrm{~K} \mathrm{~kg}^{-1}$ ) is often chosen to indicate the tropopause level (Hoskins et al., 1985) but absolute values between 1 PVU and 4 PVU have been used.

Finally, echo return power from Very High Frequency (VHF) radars may be used to identify the radar tropopause (Hooper and Arvelius, 2000). VHF radars are capable of continuous atmospheric monitoring (Gage and Green, 1979, 1982) with a much higher temporal resolution than radiosonde, ozonesonde or satellite observations, although they are limited to a few locations globally. Different algorithms have been used to determine the altitude of the tropopause from the radar echo return power, including the peak echo power (Vaughan et al., 1995; Hall et al., 2009), the peak in the echo power gradient (Vaughan et al., 1995; Hooper and Arvelius, 2000) or the absolute value of echo power (Gage and Green, 1982). Observations of the radar tropopause with temporal resolution on the order of a few hours have revealed its rich structure and altitudinal variability on subdiurnal time-scales (Nastrom et al., 1989). The Arctic VHF radar tropopause altitude has been investigated above Svalbard $\left(78^{\circ} \mathrm{N}, 16^{\circ} \mathrm{E}\right)$ (Hall et al., 2009, 2011) and Kiruna $\left(68^{\circ} \mathrm{N}, 21^{\circ} \mathrm{E}\right)$ (Hooper and Arvelius, 2000). A VHF radar was deployed at Wasa $\left(73^{\circ} \mathrm{S}, 13^{\circ} \mathrm{W}\right)$ during the Antarctic summer of 2007-08, which provided wind and turbulence observations up to the lower stratosphere. Results from this radar were used in fine-scale modelling case studies to investigate gravity waves seen in the radar data, which were shown to be generated by nearby topography (Valkonen et al., 2010; Arnault and Kirkwood, 2012); as well as a case study of a tropopause fold (Mihalikova et al., 2012). The radar echo power received is proportional to $M^{2} / z^{2}$, where $M$ is the mean vertical gradient of generalized potential refractive index (Ottersten, 1969) and $z$ is altitude. Humidity can be neglected in the UTLS so that (Doviak and Zrnic, 1984):

$M=-77.6 \times 10^{-6} \frac{p}{T} \frac{\partial \ln \theta}{\partial z}$ where $T$ is the temperature. $M$ is proportional to the vertical gradient of $\ln \theta$ and this relationship allows the detection of the tropopause (and also changes in static stability associated with frontal passages) by the radar backscattered power (Tsuda et al., 1988; Nastrom et al., 1989; May et al., 1991; Lucas et al., 2001). The upper troposphere temperature gradient usually corresponds closely to the dry adiabatic lapse rate, thus the static stability $(\propto \partial \ln \theta / \partial z)$ is small and the radar's echo returns are low. Due to the rapid increase in static stability upon the transition into the stratosphere, the radar detects a local maximum in echo power directly above the tropopause. The radar tropopause as used here is the altitude of the maximum vertical gradient of the echo power (Gage and Green, 1979; Vaughan et al., 1995). This use of vertical power gradients avoids reliance on the absolute echo power of the radar.

These different tropopause definitions are related to each other via vertical gradients in static stability and horizontal vorticity gradients (Gettelman et al., 2011). The maximum gradient in range-corrected echo return power is equivalent to the maximum vertical gradient in static stability (see above). On the other hand, the WMO, chemical and PV tropopauses correspond to various values of static stability. The WMO tropopause is defined at a particular temperature gradient, the PV tropopause is largely determined by the gradient in potential temperature at high latitudes, while the ozone tropopause is defined at a specified vertical gradient of ozone concentration. On synoptic time-scales the ozone mixing ratio is approximately materially conserved (Wirth, 2000), so the ozone tropopause should be similar to the PV tropopause altitude. Only when the tropopause sharpness is high and relative vorticity is low would the radar tropopause be expected to co-incide with the other tropopauses.

The Antarctic UTLS is different to that in other parts of the world. During winter and spring, the temperature often continues to decrease with altitude throughout the UTLS and may not reach the gradient threshold required by the lapse-rate tropopause definition criteria. This is a limitation of the WMO definition of the tropopause, which is often not suitable for Antarctic winter or spring conditions. Zängl and Hoinka (2001) noted that vertically-resolved trace gas profiles such as ozone, or a potential vorticity (PV) based tropopause could be used during polar winter, although the latter still has limitations such as defining the appropriate PV level. The altitudes of these tropopauses vary depending upon the sharpness of the tropopause inversion layer or the degree of upper tropospheric cyclonic activity (Wirth, 2001; Randel et al., 2007). The -2 PVU surface from re-analysis data was used to construct an Antarctic-wide tropopause climatology by Wilcox et al. (2011), however the significance of a winter PV tropopause was questioned. High latitude analyses of tropopause folds using PV re-analysis data indicate a distinct seasonal cycle, with more folds occurring during the winter months (Sprenger et al., 2003). 
Table 1. Radar parameters used in the experiment.

\begin{tabular}{lr}
\hline Parameter & Setting \\
\hline Beam direction & vertical \\
Pulse Repetition Frequency & $1040 \mathrm{~Hz}$ \\
Coherent Integrations & 32 \\
Range & $2.0-15.2 \mathrm{~km}$ \\
Range resolution & $300 \mathrm{~m}$ \\
Sampling rate & $8 \mathrm{~min}$ \\
\hline
\end{tabular}

Vertical profiles of UTLS variables are conventionally diagnosed relative to the height above sea level. However, the fine scale cross-tropopause structure is lost when averages are constructed because the tropopause altitude varies in space and time. In order to overcome this problem, vertical profiles of UTLS variables can be calculated relative to each individual profile's tropopause altitude, thus establishing a tropopause-relative co-ordinate system (Birner et al., 2002; Randel et al., 2007; Hegglin et al., 2009). A strong temperature inversion was found in the tropopause-relative extra-tropical climatology with a discontinuity in $N^{2}$ directly above the tropopause (Birner, 2006; Tomikawa et al., 2009). The strength of the tropopause inversion layer (TIL) is quantified by the tropopause sharpness. The sharpness $S_{\mathrm{TP}}$ is defined as (Wirth, 2000):

$S_{\mathrm{TP}}=\frac{T_{T P+\Delta z}-T_{\mathrm{TP}}}{\Delta z}-\frac{T_{\mathrm{TP}}-T_{T P-\Delta z}}{\Delta z}$

where the subscript TP indicates the tropopause and $\Delta z=$ $1 \mathrm{~km}$. Tropopause sharpness is higher during summer than during winter in the polar regions (Zängl and Hoinka, 2001). Randel and Wu (2010) suggested that increased water vapour in the polar summertime troposphere and lower stratosphere leads to stronger radiative cooling around the tropopause. This creates a stronger summer temperature inversion in the UTLS and results in a sharper tropopause.

Using two years of VHF radar echo power observations from Davis, Antarctica, we investigate the high-resolution characteristics of the Antarctic tropopause. Differences between co-located radar, radiosonde (WMO), potential vorticity and ozonesonde definitions of tropopause altitude are quantified. We demonstrate the robustness of the Antarctic VHF radar tropopause in both summer and winter even during cyclonic meteorological conditions, and quantify the seasonal variation in the occurrence frequency of tropopause folds.

\section{Data analysis}

The VHF radar located at Davis, Antarctica $\left(69^{\circ} \mathrm{S}, 78^{\circ} \mathrm{E}\right)$ operates at $55 \mathrm{MHz}$. A Doppler beam steering experiment was run between August 2009 and October 2011. We use the two years of data from September 2009-August 2011

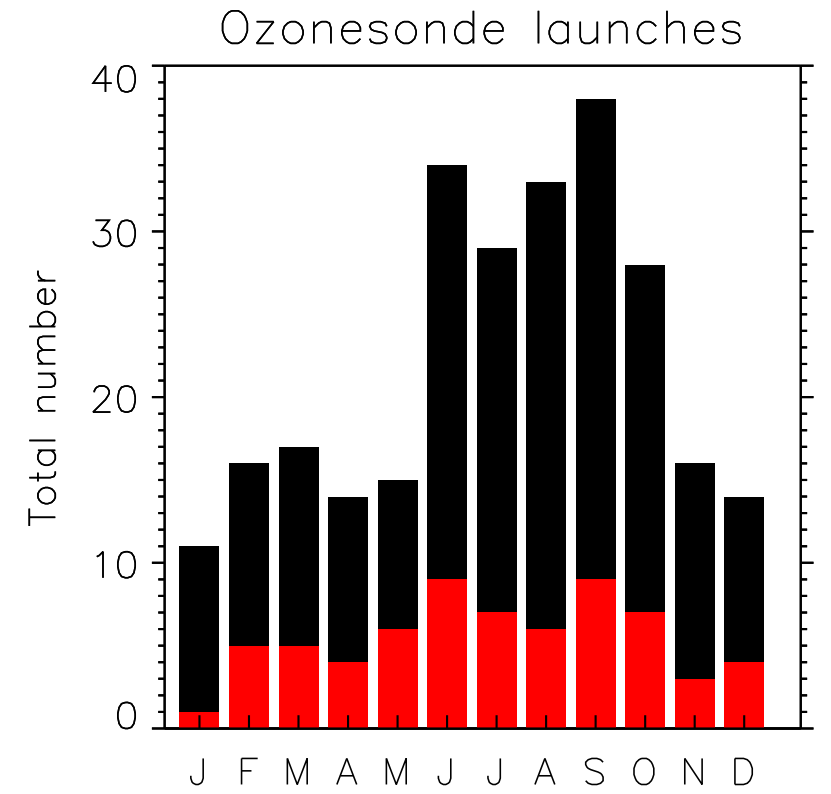

Fig. 1. Distribution of the total number of ozonesonde launches at Davis for September 2009-August 2011 (red colourbars) and February 2003-April 2012 (black colourbars).

inclusive. Details of the experimental setup relevant to this study are given in Table 1; further details of the system are presented by Morris et al. (2006). While the experiment also used off-vertical beams to provide radial velocities and thus the three-dimensional wind components, we do not discuss the wind data here because it is generally restricted to the lower troposphere. Some averaging of the original 8 minute temporal resolution power profiles is necessary because by differentiating the power, the results have a greater sensitivity to noise. To minimise this noise, the data are averaged into $2 \mathrm{~h}$ blocks and then smoothed vertically using a 3point running mean to form a power profile $P_{\text {radar }}(z)$, similar to the method of Hooper and Arvelius (2000). Local maxima in the vertical power $P_{\text {radar }}(z)$ gradient are flagged as a possible tropopause at this $z$ if the range-weighted power $z^{2} P_{\text {radar }}(z)$ is greater than the mean range-weighted power values from $-900 \mathrm{~m}$ to $-300 \mathrm{~m}$ inclusive (below, i.e. three range gates) and less than the mean range-weighted power values from $+300 \mathrm{~m}$ to $+900 \mathrm{~m}$ above. The altitude of the radar tropopause $z_{\text {radar }}$ is the altitude of the largest maximum gradient of $P_{\text {radar }}(z)$ satisfying these conditions. A few isolated $z_{\text {radar }}$ outliers are removed by constructing a $24 \mathrm{~h}$ running mean time series and removing those $z_{\text {radar }}$ which are more than 2 standard deviations outside this running mean. This outlier removal does not affect the identification of tropopause folds (see below).

Ozone is used as the tracer to define the chemical gradient tropopause and we follow the ozone tropopause $z_{\text {ozone }}$ criteria of Bethan et al. (1996), modified for Antarctic conditions 
(a) Ozone Mixing Ratio

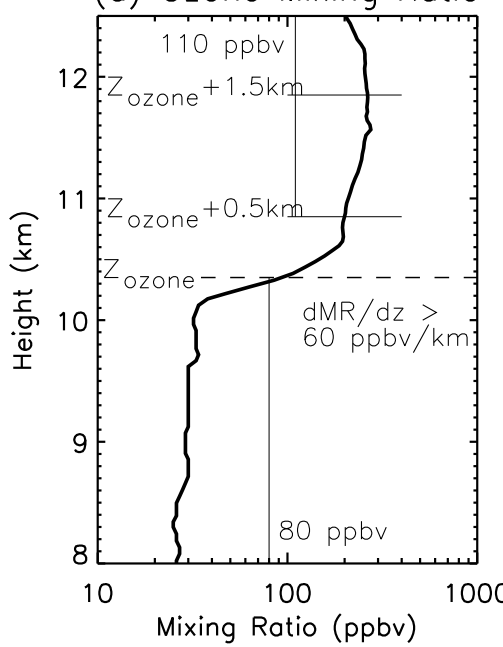

(b) Temperature

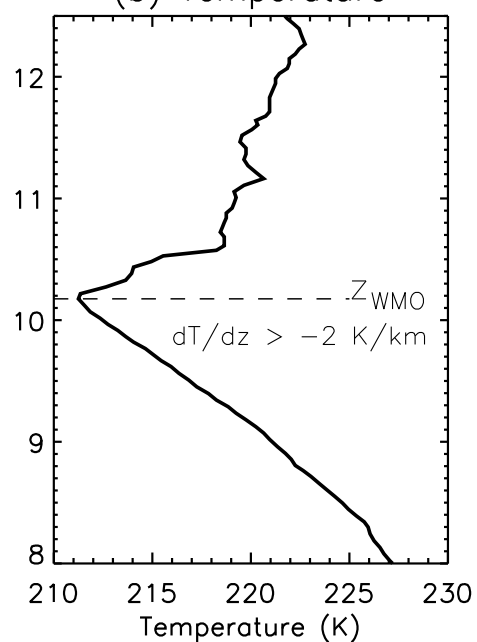

(c) Radar Echo Power

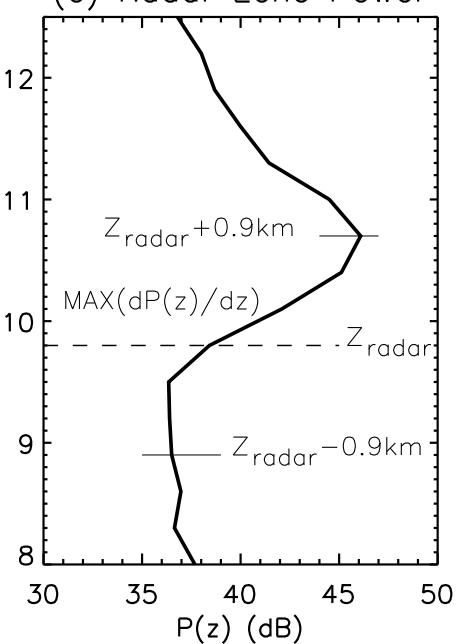

Fig. 2. Example vertical profiles of (a) ozone mixing ratio, (b) temperature and (c) radar echo power (smoothed over three range gates) on 19 March 2010. The dashed horizontal lines on each panel indicate the tropopause height determined with each method. Other annotations illustrate the tropopause detection algorithms which are described in the text.

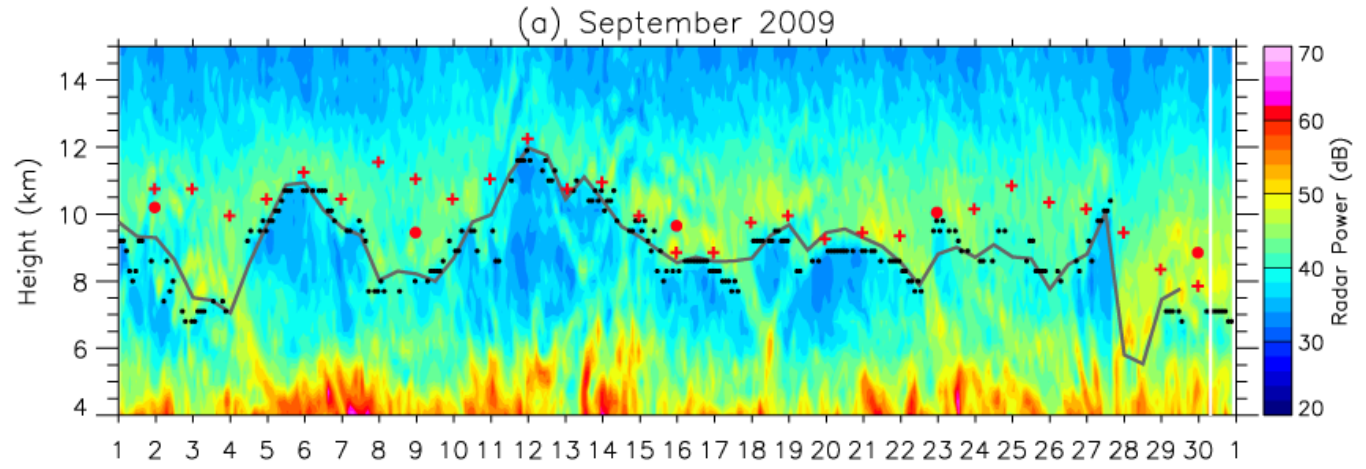

(b) March 2010

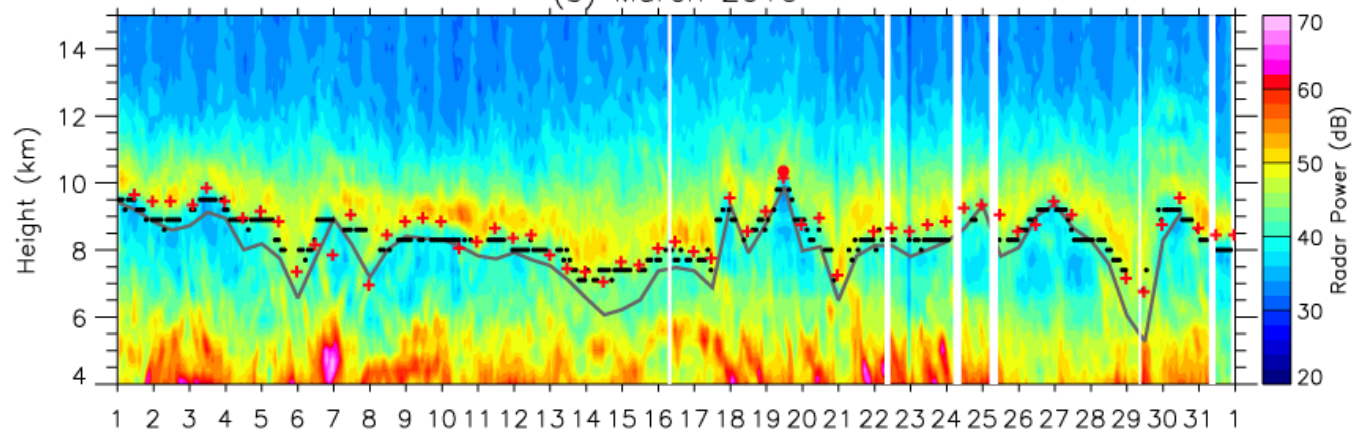

Fig. 3. September 2009 (top) and March 2010 (bottom) radar power (dB, colour scale), $z_{\mathrm{WMO}}$ (red crosses), $z_{\text {ozone }}$ (red circles), $z_{\text {radar }}$ (small black circles) and $z$ PV (grey line). Times of missing radar data are marked white and x-axis tickmarks indicate midnight UT.

by Tomikawa et al. (2009). Specifically, $z_{\text {ozone }}$ is the lowest altitude at which the vertical ozone mixing ratio gradient exceeds $60 \mathrm{ppbv} \mathrm{km}^{-1}$; the mixing ratio $>80 \mathrm{ppbv}$ and the mixing ratio at $500-1500 \mathrm{~m}$ above $z_{\text {ozone }}$ is $>110 \mathrm{ppbv}$.
Ozonesondes are launched at Davis on average once a week during the ozone hole season (June-October), but about monthly for the remainder of the year. Due to the much lower quantity of ozonesonde data compared with radiosonde and 


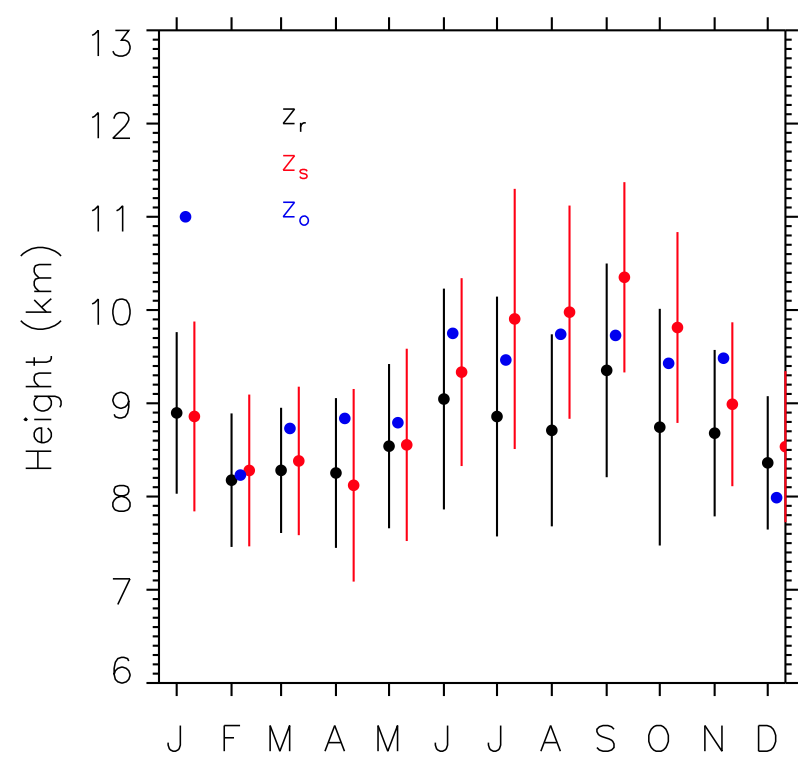

Fig. 4. The monthly mean and standard deviations of the radar tropopause (black), WMO tropopause (red, offset by +10 days) and ozone tropopause (blue, offset by +5 days, no standard deviations for clarity) for September 2009-August 2011. x-axis tickmarks indicate the middle of each month.

radar data, ozonesonde data over the nine years from February 2003 until March 2012 are used to provide sufficient ozone tropopause information for comparisons with relative vorticity. The total number of ozone launches during this period, as well as that during the September 2009-August 2011 period when radar data is available, is shown in Fig. 1. The more frequent ozonesonde launches during the ozone-hole season are clearly visible.

The WMO tropopause $z$ WMO is calculated by averaging the raw radiosonde data (which typically have a $\sim 10 \mathrm{~m}$ height resolution) into $100 \mathrm{~m}$ resolution bins. No allowance is made for the time constant of the thermistor. Subsequent references to the WMO tropopause specifically mean the lapserate tropopause calculated using radiosonde data.

The -2 PVU level of the potential vorticity provided by the European Centre for Medium-Range Weather Forecasts (ECMWF) Reanalysis-Interim (ERA-Interim) (Dee et al., 2011) dataset is used as the dynamical tropopause and in geometric altitude this is referred to as $z \mathrm{PV}$.

The ozone, WMO and radar tropopauses are illustrated using data on 19 March 2010 in Fig. 2 and are at $10.4 \mathrm{~km}$, $10.2 \mathrm{~km}$ and $9.8 \mathrm{~km}$ respectively. Temperature is measured by the ozonesonde, while the radar echo power profile is that averaged over the two hours prior to the ozonesonde launch (the two-hour average echo power profile during the flight did not provide a radar tropopause). On this day, the WMO tropopause is clearly defined with a distinct change in the temperature gradient, as is usually observed in the polar summer (Randel and $\mathrm{Wu}, 2010$ ). Both the $z_{\text {ozone }}$ and $z_{\text {radar }}$ clearly correspond to large vertical gradients in ozone mixing ratio and echo power respectively. There are some small differences in the altitudes between the three tropopauses which are due to their different definitions.

\section{Results}

\subsection{Fine-scale structure of the radar tropopause}

The radar power $P_{\text {radar }}$ is illustrated in Fig. 3 for a representative winter and summer month (September 2009 and March 2010 respectively), along with $z_{\text {radar }}, z_{\text {WMO }}, z_{\text {ozone }}$ and $z \mathrm{PV}$. For reasons related to the seasonal variability in the tropopause structure (discussed below), the extended winter season is defined as the months June-October inclusive (referred to as JJASO), and the extended summer season as December-April inclusive (DJFMA). The tropopause altitude varies on a multitude of time scales. The $z_{\mathrm{WMO}}$ is close to $z_{\text {radar }}$ during DJFMA months (Fig. 3b). Differences between $z_{\text {radar }}$ and $z_{\text {WMO }}$ during JJASO of a few kilometres are sometimes apparent (e.g. 25 September, Fig. 3a). During September 2009 there are days with weak $P_{\text {radar }}$ gradients, for example 23-27 September, although a $z_{\text {radar }}$ is usually still detectable and is similar to $z_{\mathrm{PV}}$. Sudden increases in $z_{\text {radar }}$ (e.g. 17 September 2009) are reminiscent of the tropopause folds associated with stratospheric intrusions of ozone into the troposphere identified in the Northern Hemisphere (Hocking et al., 2007). Weekly ozonesonde launches at Davis during September 2009 show that $z_{\text {ozone }}$ is slightly higher than $z_{\text {radar }}$. During March 2010 the $z_{\text {radar }}$ and $z_{\text {WMO }}$ are nearly co-incident in height, and on some days $z \mathrm{PV}$ is lower than $z_{\text {radar }}$.

\subsection{Comparisons between different tropopause definitions at Davis}

Tropopause data are combined for the two-year analysis period into monthly mean radar tropopause altitude $z_{r}$, WMO tropopause altitude $z_{s}$ and ozone tropopause $z_{o}$ in Fig. 4. The $z_{s}$ and $z_{r}$ exhibit an annual cycle, with maxima in late winter and early spring. Both monthly mean tropopauses are about $8.5 \mathrm{~km}$ altitude during late summer, but the winter monthly mean $z_{r}$ is around $9.0 \mathrm{~km}$ compared with around $10.0 \mathrm{~km}$ for $z_{s}$. The vertical bars in Fig. 4 indicate the standard deviations: larger variability in both $z_{r}$ and $z_{s}$ is evident during winter than during summer. The wintertime monthly mean $z_{o}$ are lower than $z_{s}$ but above $z_{r}$. The anomalous January $z_{o}$ is due to a single ozonesonde launched during this month at the time when $z_{r}$ was also at its highest point (not shown, but similar to the one ozonesonde launched in March 2010 with respect to $z_{r}$, see Fig. 3b).

The histogram frequency distribution of the differences in altitude between $z_{\text {radar }}$ and $z_{\text {WMO }}$ for DJFMA and JJASO are displayed in Fig. 5a. The DJFMA distribution has a mean and standard deviation difference of $(-0.2 \pm 0.4) \mathrm{km}$. The mean 

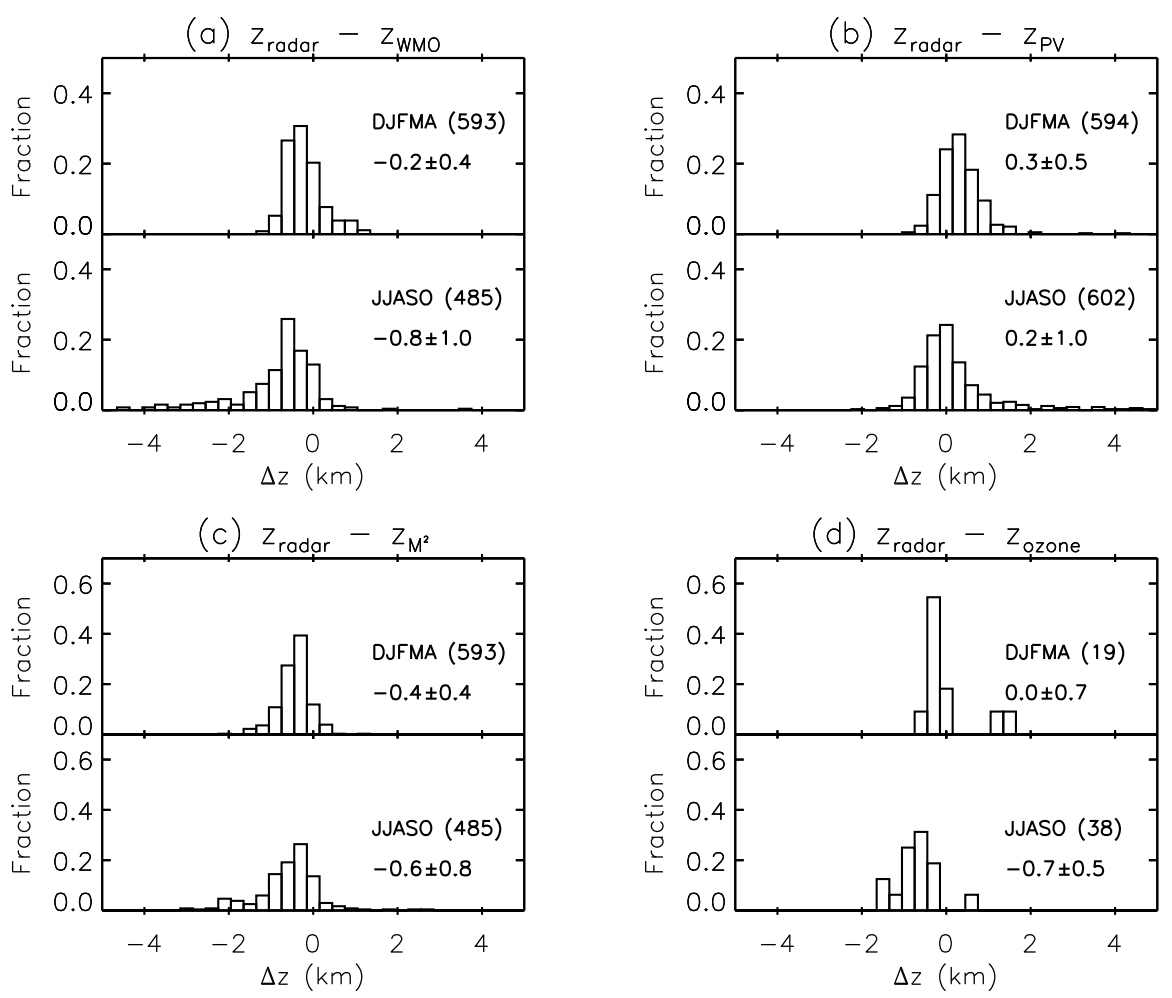

Fig. 5. DJFMA and JJASO distributions of the differences between $z_{\text {radar }}$ and (a) $z_{\mathrm{WMO}}$; (b) $z_{\mathrm{PV}}$; (c) $z_{M^{2}}$ and (d) $z_{\mathrm{ozone}}$. The numbers in brackets following the season labels indicate the number of data points used to construct the distributions. The seasonal means and standard deviations are given in each panel.

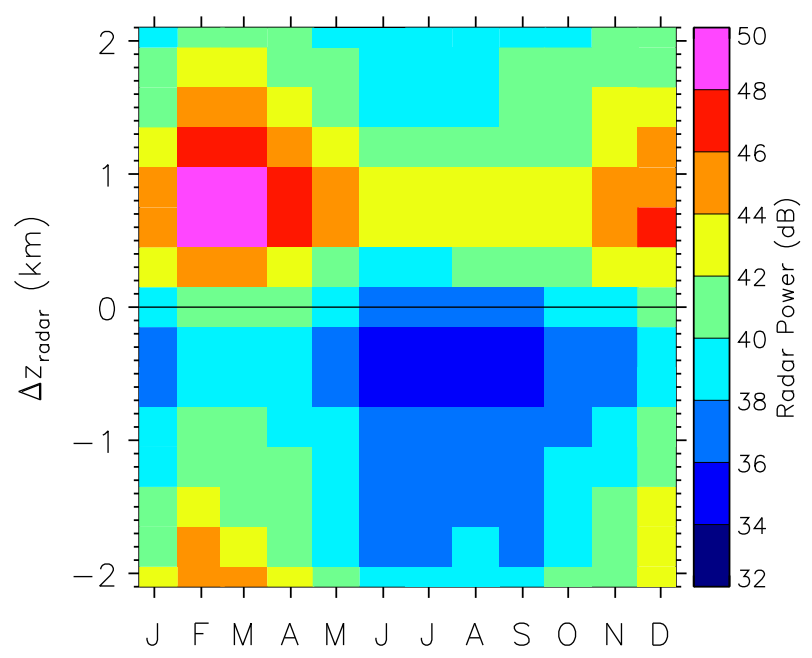

Fig. 6. The monthly mean $z_{\text {radar }}$ tropopause-relative radar power (dB). $x$-axis tickmarks indicate the middle of each month.

difference during JJASO is much larger than during DJFMA $(-0.8 \pm 1.0 \mathrm{~km})$, with most of the $z_{\text {radar }}$ lower than $z_{\text {WMO }}$. In contrast, the DJFMA and JJASO distribution between $z_{\text {radar }}$ and $z_{\mathrm{PV}}$ is similar (Fig. $5 \mathrm{~b}$ ). The $z_{\text {radar }}$ is $0.2-0.3 \mathrm{~km}$ higher than $z_{\mathrm{PV}}$ during both seasons. Fig. $5 \mathrm{~b}$ indicates the closer relation between JJASO $z_{\text {radar }}$ and $z_{\mathrm{PV}}$ than the relation between JJASO $z_{\text {radar }}$ and $z$ WMO.

Using the standard radiosonde dynamical quantities, Eq. 2 may be calculated using radiosonde data to produce $M_{\text {sonde }}$ (neglecting humidity) which can then be compared with the radar echo power returns. The $M_{\text {sonde }}$ vertical profile is used to calculate the radiosonde's refractive index tropopause $z_{M^{2}}$ in a similar manner to that for $z_{\text {radar. The }} z_{M^{2}}$ and $z_{\text {radar }}$ should agree closely because they are measuring the same atmospheric properties. Figure $5 \mathrm{c}$ shows the differences are similar and are $(-0.4 \pm 0.4) \mathrm{km}$ in DJFMA and $(-0.6 \pm 0.8) \mathrm{km}$ in JJASO.

The differences between $z_{\text {radar }}$ and $z_{\text {ozone }}$ are quantified in Fig. 5d. Note that there are fewer data points for this comparison than the previous three comparisons. The JJASO $z_{\text {ozone }}$ is $(0.7 \pm 0.5) \mathrm{km}$ higher than $z_{\text {radar }}$, while during DJFMA, $z_{\text {ozone }}$ is $(0.0 \pm 0.7) \mathrm{km}$ higher. This larger difference during winter is similar to that observed with the WMO tropopause (Fig. 5a).

Due to the relation between the radar echo power and static stability, the seasonal variation of the TIL strength is visible in the radar results. The seasonally-varying strength of the radar tropopause-relative power $P_{\text {rel }}$ is illustrated in Fig. 6. The maximum power is $600-900 \mathrm{~m}$ higher than $z_{\text {radar }}$ 

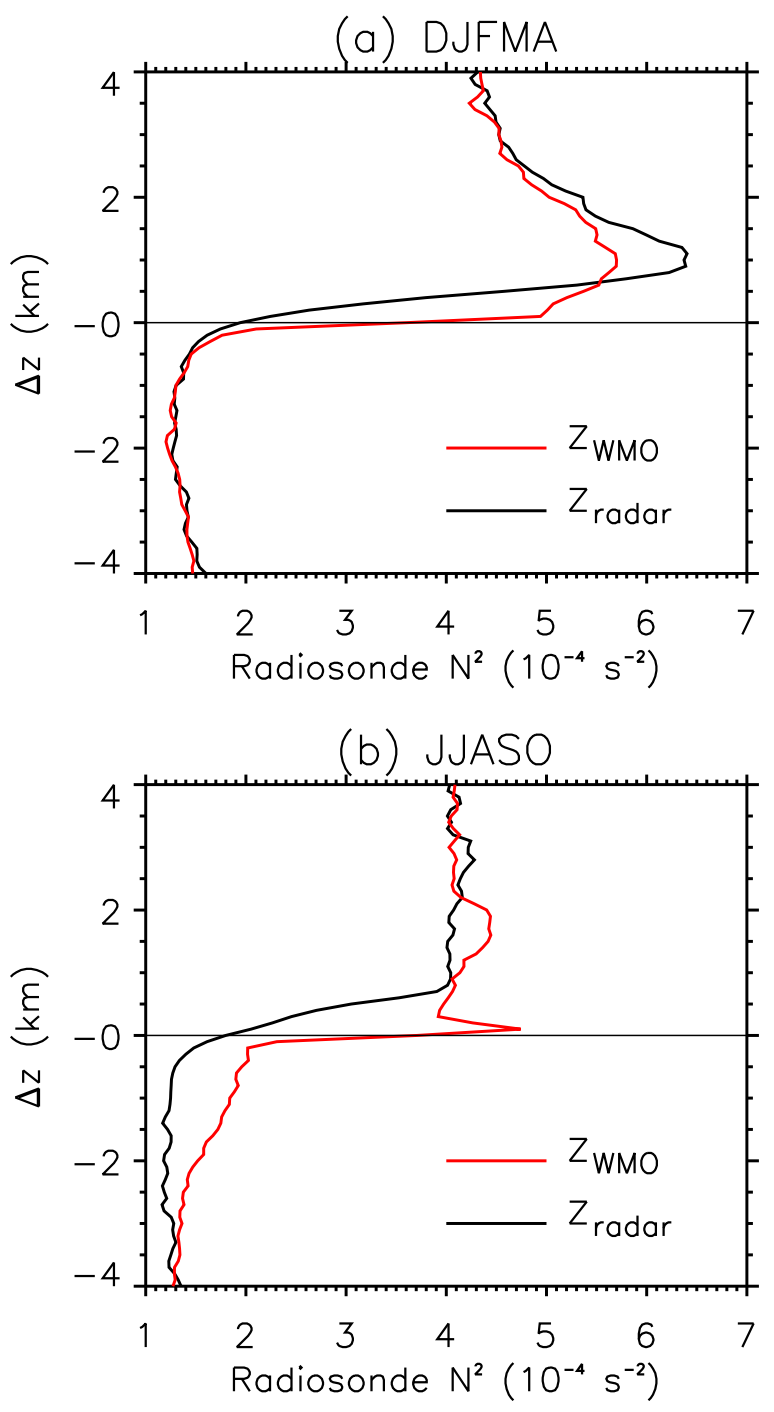

Fig. 7. The tropopause-relative profiles of radiosonde $N^{2}$ during (a) DJFMA and (b) JJASO in zWMO (red) and $z_{\text {radar }}$ (black) coordinates.

throughout the year. There is a seasonal cycle in the UTLS $P_{\text {rel }}$, with the maximum in late summer and early autumn and the minimum from late winter until early spring. The vertical gradient in UTLS power is also strongest during late summer and weakest during late winter.

The vertical profiles of mean radiosonde $N^{2}$ in WMOtropopause-relative co-ordinates are displayed for DJFMA and JJASO in Fig. 7a and b respectively. The patterns are similar to those seen at lower latitudes (Birner et al., 2002; Randel et al., 2007; Tomikawa et al., 2009). The sudden jump in $N^{2}$ upon entering the stratosphere is clearly observed. However, this increase is less-marked when the data are plotted in radar-tropopause-relative co-ordinates. The TIL is observed for DJFMA using either WMO-tropopause-relative or radar-tropopause-relative co-ordinates, but it is not seen for JJASO in the radar tropopause-relative co-ordinates.

\subsection{Tropopause relation to mesoscale meteorology}

The meteorological effect on tropopause heights are investigated by using the vertical component of relative vorticity $\zeta$ from the ERA-Interim reanalysis data (Dee et al., 2011) at the near-tropopause level of $200 \mathrm{hPa}$. This pressure level is the same as that used by Randel et al. (2007) and Randel and $\mathrm{Wu}(2010)$ and will allow direct comparisons to be made below. (Use of other pressure levels around $200 \mathrm{hPa}$ reveal similar features as those to be illustrated below). WMO and radar tropopause heights for DJFMA are plotted in Fig. 8a as a function of $\zeta$. The tropopause height is lower when there is negative vorticity and higher when there is positive vorticity (negative vorticity is associated with cyclonic conditions in the Southern Hemisphere). The difference in altitude between $z$ WMO and $z_{\text {radar }}$ is similar during both cyclonic and anticylonic conditions. The February 2003-March $2012 z_{\text {ozone }}$ are also shown in Fig. 8a and generally match the altitudes of $z_{\mathrm{WMO}}$ and $z_{\text {radar }}$. The $z_{\mathrm{PV}}$ are $0.5-1.0 \mathrm{~km}$ lower than the other tropopause altitudes during summer cyclonic conditions.

Increasingly large differences between $z_{\mathrm{WMO}}$ and $z_{\text {radar }}$ occur during increasingly strong JJASO cyclonic conditions (Fig. 8c), explaining the meteorological origin of the differences between $z$ WMO and $z_{\text {radar }}$ (Figs. $3 \mathrm{a}$ and Fig. 5a). The JJASO $z_{\text {radar }}$ and $z$ PV decrease during stronger cyclones, similar to DJFMA. Both the DJFMA and JJASO $\zeta$ distributions (Fig. 8b and Fig. 8d respectively) indicate the high southern latitude preference for cyclonic activity, consistent with Northern Hemisphere results (Randel et al., 2007).

The tropopause altitudes also vary depending upon the sharpness of the WMO tropopause, as illustrated in Fig. 9. During DJFMA, there is a slight increase in all the tropopause altitudes for an increasingly sharp WMO tropopause. On the other hand, during JJASO, the zWMO and $z_{\text {ozone }}$ remain constant when a less sharp tropopause is present, in contrast with $z_{\text {radar }}$ and $z$ PV which generally continue to decrease in altitude.

Folds are identified in radar echo power time series by a gradual decrease in tropopause altitude followed by a sudden increase as the tropopause reforms at a higher altitude (Nastrom et al., 1989). Other radar parameters may also be used as supplementary diagnostics of tropopause folds. These include horizontal wind shear and spectral width (Vaughan and Worthington, 2000; Reid and Vaughan, 2004), horizontal wind speeds (Rao et al., 2008) and aspect sensitivity (Caccia et al., 2000; Bertin et al., 2001). Horizontal winds from the radar are unavailable in the UTLS, so the tropopause detection algorithm used here combines radar echo power with winds from ERA-Interim (Dee et al., 2011).

Tropopause folds are defined at time $t$ where the median increase in $z_{\text {radar }}$ for the following six hours is at least five range gates $(1500 \mathrm{~m})$ and the $z_{\text {radar }}(t)<8.0 \mathrm{~km}$. These limits 
(a) DJFMA Tropopause

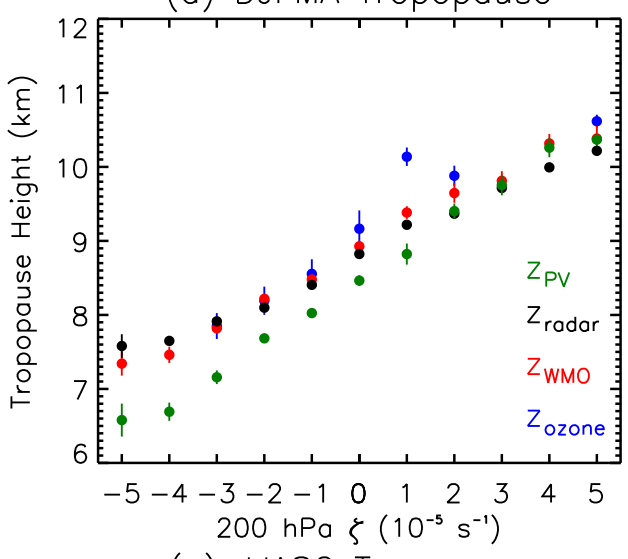

(c) JJASO Tropopause

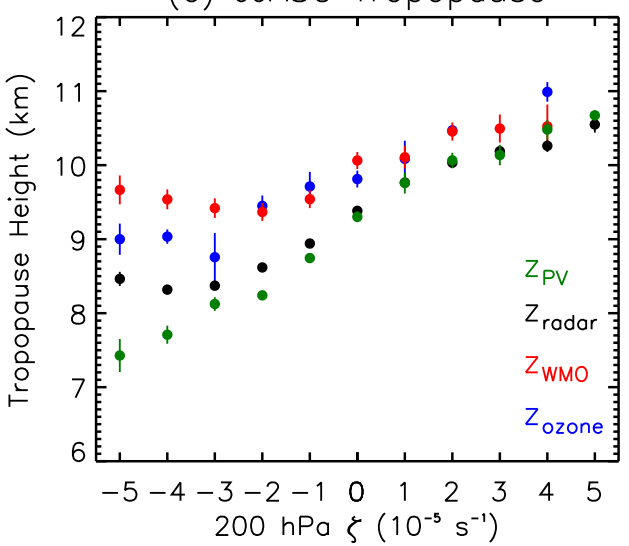

(b) DJFMA Total Observations

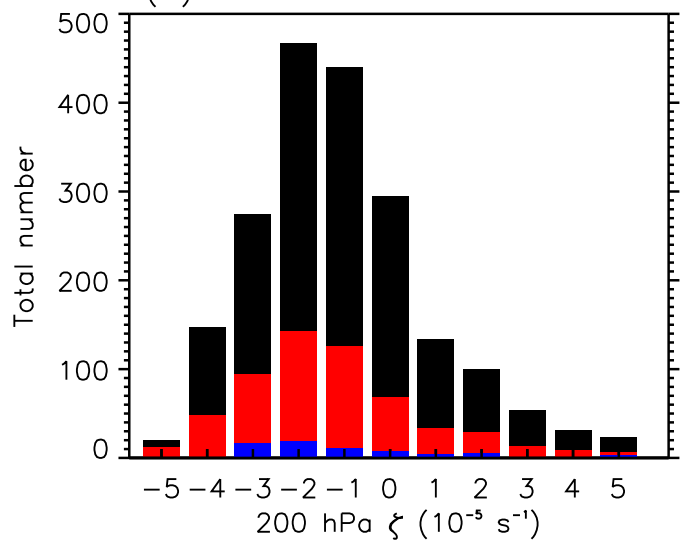

(d) JJASO Total Observations

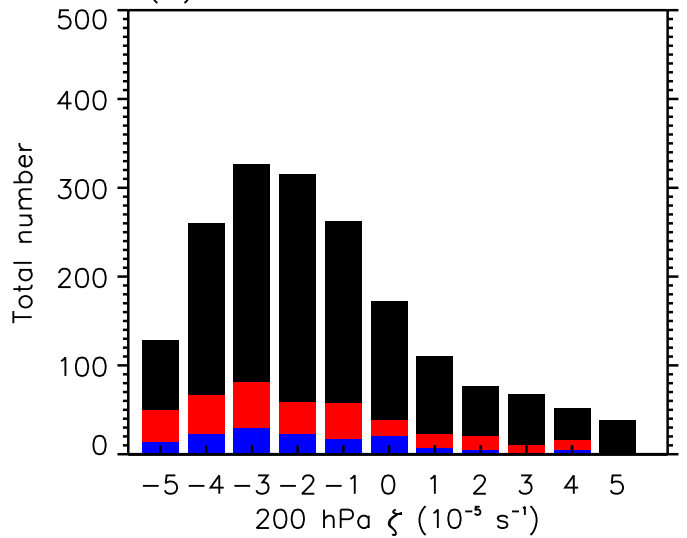

Fig. 8. The mean and standard errors of $z_{\mathrm{WMO}}$ (red), $z_{\text {radar }}$ (black), $z_{\text {ozone }}$ (blue) and $z_{\mathrm{PV}}$ (green) as a function of ERA-Interim 200 hPa $\zeta$ for (a) DJFMA and (c) JJASO. Distribution of $\zeta$ for the times of observation of $z_{\text {WMO }}$ (red), $z_{\text {radar }}$ (black) and $z_{\text {ozone }}$ (blue) during (b) DJFMA and (d) JJASO. The distribution of $\zeta$ for the times of observation of $z \mathrm{PV}$ is similar to that for $z$ WMO so is not shown.

may be varied without much change in the number of fold detections. However, a six-hourly median increase in $z_{\text {radar }}$ of more than three range gates avoids mis-assignment of a fold where the tropopause height variation is actually due to real, but small-scale tropopause variability. To be classified as a fold, a jet stream in the upper troposphere with wind speeds $\geq 30 \mathrm{~m} \mathrm{~s}^{-1}$ must also be present.

A tropopause fold is identified on 29 March 2010 (see Fig. 3b). The large change in altitude corresponds with a UTLS jet, where wind speeds exceed $30 \mathrm{~m} \mathrm{~s}^{-1}$. Occasionally, weak UTLS winds preclude the classification of a tropopause fold despite the presence of a descending layer of enhanced $P(z)$ and a corresponding increase in $z_{\text {radar }}$. Such an event occurs on 22 September 2009 (Fig. 3a).

The monthly mean number of tropopause folds for September 2009-August 2011 is presented in Fig. 10. While this two-year dataset may be too short to provide a climatology of monthly folds, the difference between DJFMA and JJASO is clearly apparent. The average number of folds dur- ing DJFMA is 0.6 per month which nearly triples to 1.6 per month during JJASO.

\section{Discussion}

The Davis VHF radar is able to continuously monitor the tropopause, allowing quantification of differences between the radar and other tropopause definitions. We find that $z_{\text {radar }}$ provides a distinct measure of the height of the polar tropopause that is valid all year. The $z_{\text {radar }}, z_{\text {ozone }}$ and $z_{\mathrm{PV}}$ decrease during increasingly strong JJASO cyclones (Fig. 8), while $z_{\text {radar }}$ and $z_{\mathrm{PV}}$ generally decrease in altitude with less sharp JJASO tropopauses (Fig. 9). We also find that the strength of the inversion layer increases with increasingly strong anticylonic conditions (Randel et al., 2007; Randel and $\mathrm{Wu}, 2010)$.

Wilcox et al. (2011) used the -2 PVU surface from ERAInterim data to construct an Antarctic-wide tropopause climatology. Fig. $5 \mathrm{~b}$ indicates that $z_{\text {radar }}$ and $z_{\mathrm{PV}}$ 

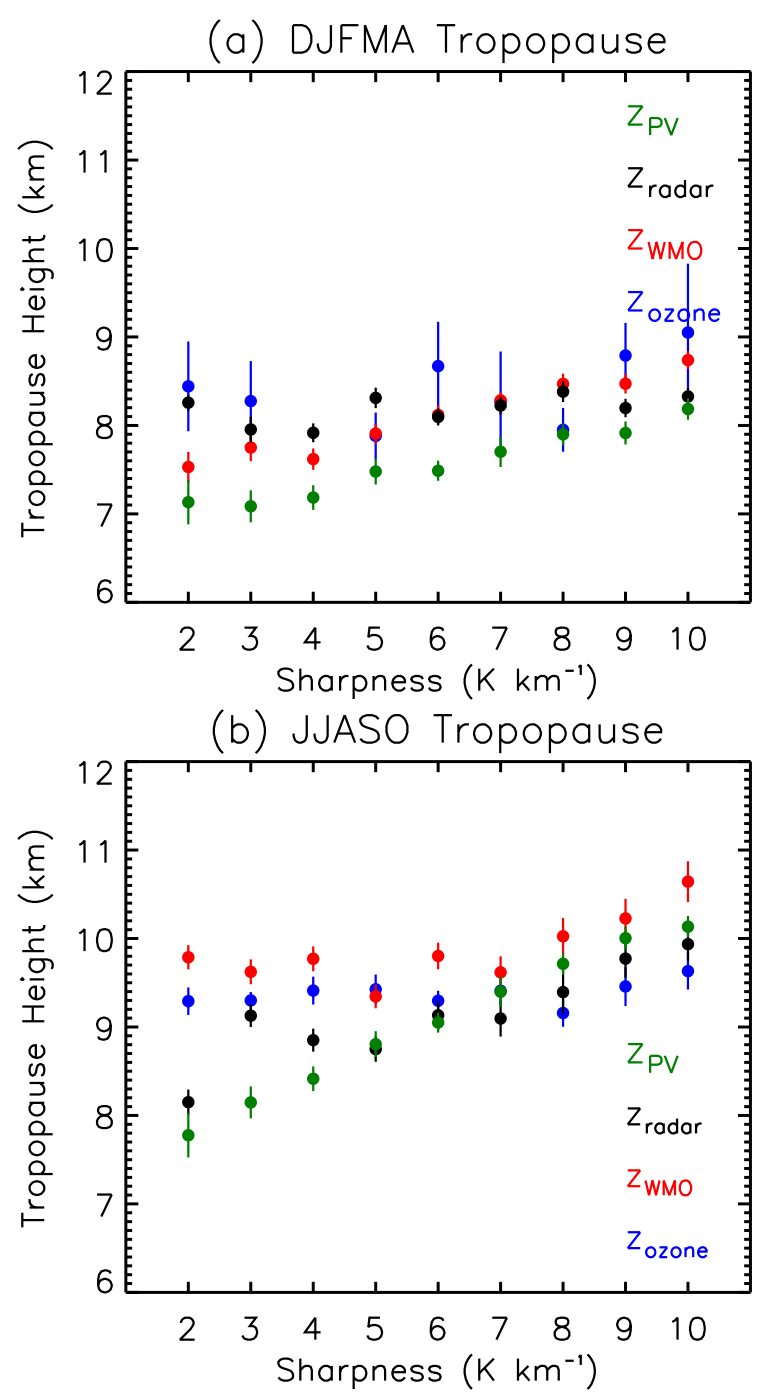

Fig. 9. The mean and standard errors of $z_{\mathrm{WMO}}$ (red), $z_{\text {radar }}$ (black), $z_{\text {ozone }}$ (blue) and $z_{\mathrm{PV}}$ (green) as a function of the tropopause sharpness for (a) DJFMA and (c) JJASO.

generally correspond closely in altitude with a mean difference close to zero and an approximately Gaussian distribution for both seasons. The $z_{\text {radar }}$ is dependent upon the maximum vertical gradient in static stability, while $z \mathrm{PV}$ (at high latitudes) is mostly dependent upon the vertical gradient in potential temperature, which is proportional to the static stability.

The post-summer solstice maximum and the post-winter solstice minimum Davis radar tropopause-relative power (Fig. 6) are consistent with the timing of Antarctic-wide radiosonde and satellite measurements of maxima in static stability, UTLS water vapour and the strength of the polar tropopause inversion layer (Tomikawa et al., 2009; Randel and $\mathrm{Wu}, 2010)$.

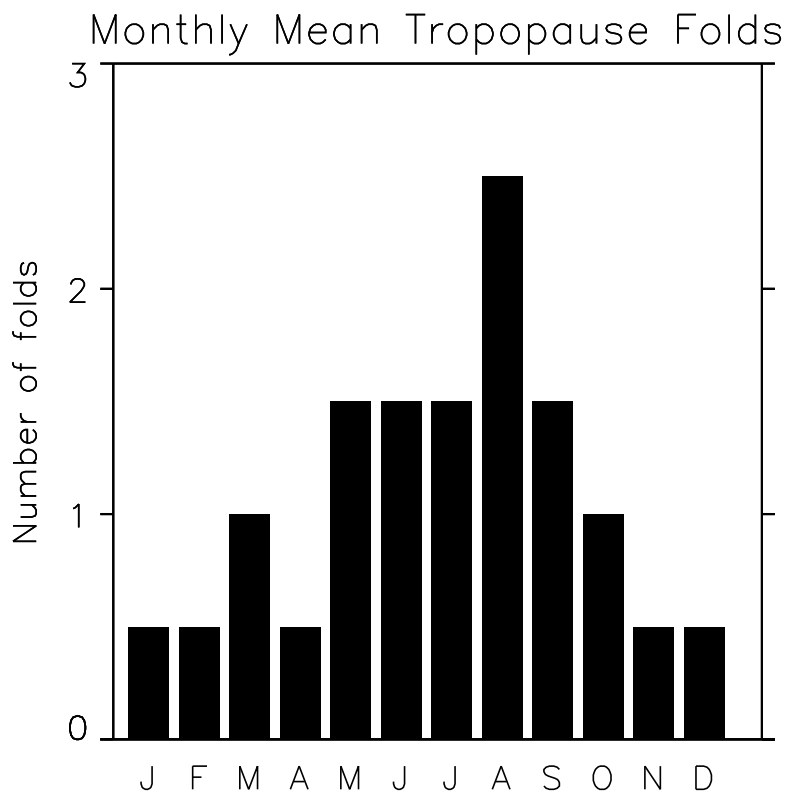

Fig. 10. The monthly mean number of folds during September 2009-August 2011.

Climatological means in traditional sea-level pressurebased co-ordinates tend to smear out details of the UTLS structure, such as the TIL identified using a lapse-rate tropopause-relative co-ordinate system (Birner et al., 2002; Birner, 2006; Randel et al., 2007), and cloud-top height (Pan and Munchak, 2011). In particular, the sharp increase in $N^{2}$ (Fig. 7) is seen in the WMO tropopause because it is calculated at a defined temperature gradient (i.e. proportional to static stability), rather than in the maximum static stability gradient. The radar tropopause-relative profiles of radiosonde $N^{2}$ result in the vanishing of the TIL and of the maximum in $N^{2}$ directly above the tropopause during JJASO (Fig. 7b). The JJASO structure of $N^{2}$ in radar tropopause based coordinates is similar to $N^{2}$ relative to the PV tropopause during cyclonic conditions (Wirth, 2003), indicating the effects that meteorological disturbances have on $z_{\text {radar }}$.

The mean difference in altitude between $z_{\text {radar }}$ and $z_{\mathrm{PV}}$ is small (Fig. 5b), with increasingly large differences during

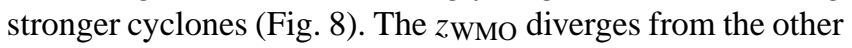
tropopause altitudes during winter when there is strong upper troposphere cyclonic activity (Fig. 8c) and when the sharpness of the tropopause is low (Fig. 9b). The descent in altitude of $z_{\text {radar }}$ often co-incides with large differences from the altitude of $z_{\text {WMO }}$ (Fig. 3a). Randel and Wu (2010) discussed Arctic average summertime GPS radio occultation temperature WMO tropopause heights as a function of $\zeta$ and showed the same relationship as that observed with radiosonde and radar at Davis. During the Northern Hemisphere mid-latitude $\left(30^{\circ}-60^{\circ} \mathrm{N}\right)$ winter, the WMO tropopause decreased in altitude for weaker anticyclonic activity and remained relatively 
constant $(<0.5 \mathrm{~km}$ variability) under cyclonic conditions (Randel et al., 2007). The WMO tropopause altitude at Davis is also approximately constant for cyclonic conditions (Fig. 8c). This separation of the altitudes of the WMO and PV tropopause during strongly cyclonic conditions was modelled by Wirth $(2000,2001)$. Large differences between ozone and WMO tropopauses reported by Bethan et al. (1996) were associated with indefinite WMO tropopauses and cyclonic conditions, as they are at Davis between WMO, ozone and PV tropopauses. The DJFMA results at $69^{\circ} \mathrm{S}$ (Fig. 8a) agree with the $70^{\circ}-90^{\circ} \mathrm{N}$ summertime GPS WMO tropopause height relationship with $\zeta$ (Randel and $\mathrm{Wu}$, 2010).

The JJASO peak in the number of tropopause folds seen at Davis is similar to the seasonal cycle observed by radar in northern Sweden (Rao et al., 2008) and more generally in global ECMWF data (Sprenger et al., 2003) in the high latitudes. The region from $60^{\circ} \mathrm{S}$ to the Antarctic coastline at $60^{\circ} \mathrm{E}-100^{\circ} \mathrm{E}$ (encompassing Davis) has the highest percentage of tropopause folds during winter poleward of $60^{\circ} \mathrm{S}$ (Sprenger et al., 2003), which was attributed to the coincident location of the climatological maximum of moving cyclones.

\section{Conclusions}

Echo power data from the VHF radar located at Davis, Antarctica for the period September 2009-August 2011 inclusive are used to characterise the seasonal structure and variability of the radar tropopause. The radar has the ability to continuously monitor the radar tropopause with high temporal resolution, including during polar winter under cyclonic and anti-cyclonic conditions.

Co-located radiosonde and ozonesonde profiles provide the data for calculation of the WMO and chemical tropopauses at Davis. Radar tropopauses are $(0.2 \pm 0.4) \mathrm{km}$ lower than WMO tropopauses during DJFMA and are $(0.8 \pm$ $1.0) \mathrm{km}$ lower during JJASO. The times of largest differences between the WMO and radar tropopause altitudes occur during JJASO cyclonic activity. The ozone, PV and radar tropopause altitudes decrease with increasingly strong cyclonic activity, unlike the WMO tropopause altitudes which are nearly constant during increasingly strong cyclonic conditions. The altitude of the $-2 \mathrm{PVU}$ surface, used here as the PV tropopause, is $(0.3 \pm 0.5) \mathrm{km}$ lower than the radar tropopause during DJFMA and $(0.2 \pm 1.0) \mathrm{km}$ lower during JJASO.

The frequency of tropopause folds increases about threefold from 0.6 per month during DJFMA to 1.6 per month during JJASO. This indicates an increase in STE events during the ozone-hole season. Given the upper tropospheric frontogenesis, cyclogenesis and STE implications of tropopause folds (Sprenger et al., 2003), a more detailed investigation of these folds at Davis may shed further light on STE processes in the high southern latitudes.

Acknowledgements. We thank the Davis engineers for their efforts in maintaining the VHF radar and the Bureau of Meteorology staff who launched the radiosondes and ozonesondes. ERA-Interim data were obtained through the ECMWF data server. This research was conducted for projects 737, 2325 and 3140 of the Australian Antarctic programme. The valuable comments of two anonymous reviewers are much appreciated.

Edited by: G. Vaughan

\section{References}

Arnault, J. and Kirkwood, S.: Dynamical influence of gravity waves generated by the Vestfjella Mountains in Antarctica: radar observations, fine-scale modelling and kinetic energy budget analysis, Tellus A, 64, 17261, doi:10.3402/tellusa.v64i0.17261, 2012.

Bertin, F., Campistron, B., Caccia, J. L., and Wilson, R.: Mixing processes in a tropopause fold observed by a network of ST radar and lidar, Ann. Geophysicae, 19, 953-963, 2001.

Bethan, S., Vaughan, G., and Reid, S. J.: A comparison of ozone and thermal tropopause heights and the impact of tropopause definition on quantifying the ozone content of the troposphere, Q. J. R. Meteorol. Soc., 122, 929-944, 1996.

Birner, T.: Fine-scale structure of the extratropical tropopause region, J. Geophys. Res., 111, D04104, doi:10.1029/2005JD006301, 2006.

Birner, T., Dörnbrack, A., and Schumann, U.: How sharp is the tropopause at midlatitudes?, Geophys. Res. Lett., 29, 1700, doi:10.1029/2002GL015142, 2002.

Caccia, J. L., Bertin, F., Campistron, B., Klaus, V., Pointin, Y., van Baelen, J., and Wilson, R.: Cut-off low monitoring by the French VHF-ST radar network during the ESTIME campaign, J. Atmos. Sol. Terr. Phys., 62, 639-651, 2000.

Dee, D. P., Uppala, S. M., Simmons, A. J., Berrisford, P., Poli, P., Kobayashi, S., Andrae, U., Balmaseda, M. A., Balsamo, G., Bauer, P., Bechtold, P., Beljaars, A. C. M., van de Berg, L., Bidlot, J., Bormann, N., Delsol, C., Dragani, R., Fuentes, M., Geer, A. J., Haimberger, L., Healy, S. B. Hersbach, H. , Holm, E. V., Isaksen, L. , Kallberg, P., Kohler, M., Matricardi, M., McNally, A. P., Monge-Sanz, B. M., Morcrette, J.-J., Park, B.-K., Peubey, C., de Rosnay, P., Tavolato, C. Thepaut, J.-N., and Vitart, F.: The ERA-Interim reanalysis: configuration and performance of the data assimilation system, Q. J. R. Meteorol. Soc., 137, 553-597, doi:10.1002/qj.828, 2011.

Doviak, R. J. and Zrnic, D. S.: Doppler radar and weather observations, Academic Press, 1984.

Gage, K. S. and Green, J. L.: Tropopause detection by partial specular reflection with very high frequency radar, Science, 203, 12381240, 1979.

Gage, K. S. and Green, J. L.: An objective method for the determination of tropopause height from VHF radar observations, J. Appl. Meteor., 21, 1150-1154, 1982.

Gettelman, A., Hoor, P., Pan, L. L., Randel, W. J., Hegglin, M. I., and Birner, T.: The extratropical upper troposphere 
and lower stratosphere, Rev. Geophys., 49, RG3003, doi:10.1029/2011RG000355, 2011.

Hall, C. M., Röttger, J., Kuyeng, K., Sigernes, F., Claes, S., and Chau, J.: First results of the refurbished SOUSY radar: Tropopause altitude climatology at $78^{\circ} \mathrm{N}, 16^{\circ} \mathrm{E}, 2008$, Radio Sci., 44, RS5008, doi:10.1029/2009RS004144, 2009.

Hall, C. M., Hansen, G., Sigernes, F., and Kuyeng Ruiz, K. M.: Tropopause height at $78^{\circ} \mathrm{N} 16^{\circ} \mathrm{E}$ : average seasonal variation 2007-2010, Atmos. Chem. Phys., 11, 5485-5490, doi:10.5194/acp-11-5485-2011, 2011.

Hegglin, M. I., Boone, C. D., Manney, G. L., and Walker, K. A.: A global view of the extratropical tropopause transition layer from Atmospheric Chemistry Experiment Fourier Transform Spectrometer $\mathrm{O}_{3}, \mathrm{H}_{2} \mathrm{O}$ and $\mathrm{CO}$, J. Geophys. Res., 114, D00B11, doi:10.1029/2008JD009984, 2009.

Hocking, W. K., Carey-Smith, T., Tarasick, D. W., Argall, P. S., Strong, K., Rochon, Y., Zawadzki, I., and Taylor, P. A.: Detection of stratospheric ozone intrusions by windprofiler radars, Nature, 450, 281-284, doi:10.1038/nature06312, 2007.

Holton, J. R., Haynes, P. H., McIntyre, M. E., Douglass, A. R., Rood, R. B., and Pfister, L.: Stratosphere - Troposphere Exchange, Rev. Geophys., 33, 403-439, 1995.

Hooper, D. A. and Arvelius, J.: Monitoring of the Arctic winter tropopause: A comparison of radiosonde, ozonesonde and MST radar observations, in: 9th international workshop on technical and scientific aspects of MST radar, Sci. Comm. on Sol. Terr. Phys., Toulouse, France, 2000.

Hoskins, B. J., McIntyre, M. E., and Robertson, A. W.: On the use and significance of isentropic potential vorticity maps, Q. J. R. Meteorol. Soc., 111, 877-946, 1985.

Lucas, C., May, P. T., and Vincent, R. A.: An algorithm for the detection of fronts in wind profiler data, Weather Forecast., 16, 234-247, 2001.

May, P. T., Yamamoto, M., Fukao, S., Sato, T., Kato, S., and Tsuda, T.: Wind and reflectivity fields around fronts observed with a VHF radar, Radio Sci., 26, 1245-1249, 1991.

Mihalikova, M., Kirkwood, S., Arnault, J., and Mikhaylova, D.: Observation of a tropopause fold by MARA VHF wind-profiler radar and ozonesonde at Wasa, Antarctica: comparison with ECMWF analysis and a WRF model simulation, Ann. Geophys., 30, 1411-1421, doi:10.5194/angeo-30-1411-2012, 2012.

Morris, R. J., Murphy, D. J., Vincent, R. A., Holdsworth, D. A., Klekociuk, A. R., and Reid, I. M.: Characteristics of the wind, temperature and PMSE field above Davis, Antarctica, J. Atmos. Sol. Terr. Phys., 68, 418-435, 2006.

Nastrom, G. D., Green, J. L., Peterson, M. R., and Gage, K. S.: Tropopause folding and the variability of the tropopause height as seen by the Flatland VHF radar, J. Appl. Meteor., 28, 12711281, 1989.

Ottersten, H.: Atmospheric structure and radar backscattering in clear air, Radio Sci., 4, 1247-1249, 1969.

Pan, L. L. and Munchak, L. A.: Relationship of cloud top to the tropopause and jet structure from CALIPSO data, J. Geophys. Res., 116, D12201, doi:10.1029/2010JD015462, 2011.

Pan, L. L., Randel, W. J., Gary, B. L., Mahoney, M. J., and Hintsa, E. J.: Definitions and sharpness of the extratropical tropopause: A trace gas perspective, J. Geophys. Res., 109, D23103, doi:10.1029/2004JD004982, 2004.
Pan, L. L., Randel, W. J., Gille, J. C., Hall, W. D., Nardi, B., Massie, S., Yudin, V., Khosravi, R., Konopka, P., and Tarasick, D.: Tropospheric intrusions associated with the secondary tropopause, J. Geophys. Res., 114, D10302, doi:10.1029/2008JD011374, 2009.

Randel, W. J. and Wu, F.: The polar summer tropopause inversion layer, J. Atmos. Sci., 67, 2572-2581, doi:10.1175/2010JAS3430.1, 2010.

Randel, W. J., Wu, F., and Forster, P.: The extratropical tropopause inversion layer: Global observations with GPS data, and a radiative forcing mechanism, J. Atmos. Sci., 64, 4489-4496, 2007.

Rao, T. N., Arvelius, J., and Kirkwood, S.: Climatology of tropopause folds over a European Arctic station (Esrange), J. Geophys. Res., 113, D00B03, doi:10.1029/2007JD009638, 2008.

Reid, H. J. and Vaughan, G.: Convective mixing in a tropopause fold, Q. J. R. Meteorol. Soc., 130, 1195-1212, doi:10.1256/qj.03.21, 2004.

Sprenger, M., Maspoli, M. C., and Wernli, H.: Tropopause folds and cross-tropopause exchange: A global investigation based upon ECMWF analyses for the time period March 2000 to February 2001, J. Geophys. Res., 108, 8518, doi:10.1029/2002JD002587, 2003.

Sprenger, M., Wernli, H., and Bourqui, M.: Stratosphere - troposphere exchange and its relation to potential vorticity streamers and cutoffs near the extratropical tropopause, J. Atmos. Sci., 64, 1587-1603, doi:10.1175/JAS3911.1, 2007.

Stohl, A., Bonasoni,P., Cristofanelli, P., Collins, W., Feichter, J., Frank, A., Forster, C., Gerasopoulos, E., Gaggeler,H., James, P., Kentarchos, T., Kromp-Kolb, H., Kruger, B., Land, C., Meloen, J., Papayannis, A., Priller, A., Seibert, P., Sprenger, M., Roelofs, G. J., Scheel, H. E., Schnabel, C., Siegmund, P., Tobler, L., Trickl, T., Wernli, H., Wirth, V., Zanis, P., and Zerefos, C.: Stratosphere-troposphere exchange: A review, and what we have learned from STACCATO, J. Geophys. Res., 8516, doi:10.1029/2002JD002490, 2003.

Tomikawa, Y., Nishimura, Y., and Yamanouchi, T.: Characteristics of tropopause and tropopause inversion layer in the polar region, Sci. Online Lett. Atmos., 5, 141-144, doi:10.2151/sola.2009036, 2009.

Tsuda, T., May, P. T., Sato, T., Kato, S., and Fukao, S.: Simultaneous observations of reflection echoes and refractive index gradient in the troposphere and lower stratosphere, Radio Sci., 23, 655-665, 1988.

Valkonen, T., Vihma, T., Kirkwood, S., and Johansson, M.: Finescale modelling simulation of gravity waves generated by Basen nunatak in Antarctica, Tellus, 62A, 319-332, 2010.

Vaughan, G. and Timmis, C.: Transport of near-tropopause air into the lower midlatitude stratosphere, Q. J. R. Meteorol. Soc., 124, 1559-1578, 1998.

Vaughan, G. and Worthington, R. M.: Break-up of a stratospheric streamer observed by MST radar, Q. J. R. Meteorol. Soc., 126 , 1751-1769, 2000.

Vaughan, G., Howells, A., and Price, J. D.: Use of MST radars to probe the mesoscale structure of the tropopause, Tellus, 47A, 759-765, 1995.

Wernli, H. and Sprenger, M.: Identification and ERA-15 climatology of potential vorticity streamers and cutoffs near the extratropical tropopause, J. Atmos. Sci., 64, 1569-1586, doi:10.1175/JAS3912.1, 2007. 
Wilcox, L. J., Hoskins, B. J., and Shine, K. P.: A global blended tropopause based on ERA data. Part I: Climatology, Q. J. R. Meteorol. Soc., 138, 561-575, 2011.

Wirth, V.: Thermal versus dynamical tropopause in uppertropospheric balanced flow anomalies, Q. J. R. Meteorol. Soc., 299-317, 2000.

Wirth, V.: Cyclone - Anticyclone asymmetry concerning the height of the thermal and the dynamical tropopause, J. Atmos. Sci., 58, 26-37, 2001.
Wirth, V.: Static stability in the extratropical region, J. Atmos. Sci., 60, 1395-1409, 2003.

World Meteorological Organization: Meteorology - a threedimensional science: Second session of the Commission for Aerology, 1957.

Zängl, G. and Hoinka, K. P.: The tropopause in the polar regions, J. Climate, 14, 3117-3139, 2001. 